\title{
One-year outcomes after rapid-deployment aortic valve replacement
}

\author{
Christopher Young, MD, ${ }^{a}$ Günther Laufer, MD, ${ }^{\mathrm{b}}$ Alfred Kocher, MD, ${ }^{\mathrm{b}}$ Marco Solinas, MD, ${ }^{\mathrm{c}}$ \\ Francesco Alamanni, MD, ${ }^{\mathrm{d}}$ Gianluca Polvani, MD, ${ }^{\mathrm{d}}$ Bruno K. Podesser, MD, ${ }^{\mathrm{e}}$ Jose Ignacio Aramendi, MD, \\ Jose Arribas, MD, ${ }^{g}$ Olivier Bouchot, MD, ${ }^{\mathrm{h}}$ Ugolino Livi, MD, ${ }^{\mathrm{i}}$ Massimo Massetti, MD, ${ }^{\mathrm{j}}$ Kim Terp, MD, ${ }^{\mathrm{k}}$ \\ Christophe Giot, $\mathrm{MD},{ }^{1}$ and Mattia Glauber, $\mathrm{MD}^{\mathrm{m}}$
}

\section{ABSTRACT}

Objective: The goals of rapid-deployment aortic valve replacement include facilitation of minimally invasive surgery and reduced aortic crossclamp time. We report the short-term outcomes of a series of 493 patients undergoing rapiddeployment aortic valve replacement with the EDWARDS INTUITY valve system (Edwards Lifesciences, LLC, Irvine, Calif).

Methods: Assessing Standard oF Care and Clinical Outcomes UsiNg the EDWARDS INTUITY VAlve SysTem in a European multI-center, Active, pOstmarket surveillaNce Study was a prospective, multicenter $(n=26)$ European registry designed to evaluate the safety and performance of the valve system. During rapid-deployment aortic valve replacement, device technical success and crossclamp time were assessed. Procedural outcomes, hemodynamic performance, and various adverse events and clinical outcomes were evaluated up to 2 years.

Results: Between 2012 and 2014, 493 of 517 enrolled patients successfully received implants with the study valve (95.4\% technical success). Mean crossclamp times for 163 full sternotomies, 128 mini-upper sternotomies, and 36 right anterior thoracotomies isolated aortic valve replacements were 47.3, 52.0, and 73.3 minutes, respectively. Mean follow-up was 1.8 years, with 870 total patient-years of follow-up. Mean effective orifice area increased from 0.72 (baseline) to $1.88 \mathrm{~cm}^{2}$, and mean pressure gradient decreased from 47.6 to $9.6 \mathrm{~mm} \mathrm{Hg}$ (1 year). Mean effective orifice area index increased $\left(0.39-1.01 \mathrm{~cm}^{2} / \mathrm{m}^{2}\right.$ ), and 28 of 287 patients $(9.8 \%)$ exhibited severe prosthesis-patient mismatch at 1 year. After 1 year, $68.1 \%$ and $21.7 \%$ of patients were in New York Heart Association class I and II, respectively. Freedom from death, major bleeding, major perivalvular leak, reoperation, and device explant at 1 year were $0.935,0.939,0.976$, 0.975 , and 0.983 , respectively.

Conclusions: These results demonstrate commendable safety and performance of the test valve system over the short term in a broad European setting. ( $\mathrm{J}$ Thorac Cardiovasc Surg 2018;155:575-85)

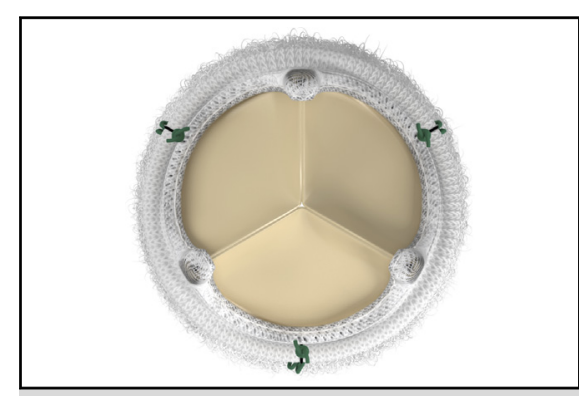

The EDWARDS INTUITY (Edwards Lifesciences, LLC, Irvine, Calif) valve and delivery system.

\section{Central Message}

The EDWARDS INTUITY (Edwards Lifesciences, LLC, Irvine, Calif) rapiddeployment aortic valve system was safe and effective through 2 years of follow-up in a broad European registry setting.

\section{Perspective}

AVR with rapid-deployment valves brings the hope of reduced XCT and facilitation of MIS We report the short-term clinical and hemodynamic outcomes of a new rapid-deployment valve system in a broad European registry setting. The results confirm the valve system to be safe and effective.

See Editorial Commentary page 586

\footnotetext{
From the 'St Thomas' Hospital, Cardiac Surgery Department, London, United Kingdom; 'Allgemeines Krankenhaus Wien, Cardiac Surgery Department, Vienna, Austria; 'Ospedale Del Cuore "G. Pasquinucci," Cardiac Surgery Department, Massa, Italy; ${ }^{\mathrm{d} C e n t r o}$ Cardiologico Monzino, Cardiac Surgery Department, Milan, Italy; ${ }^{\mathrm{e}}$ Landesklinikum St Pölten, Cardiac Surgery Department, St Pölten, Austria; ${ }^{\mathrm{f}}$ Centro Sanitario Hospital Universitario Cruces, Cardiac Surgery Department, Barakaldo, Spain; ${ }^{\mathrm{g}}$ Hospital Universitario Virgen de La Arrixaca, Cardiac Surgery Department, Murcia, Spain; ${ }^{\text {h}} \mathrm{CHU}$ du Bocage, Cardiac Surgery Department, Dijon, France; i Santa Maria della Misericordia, Cardiac Surgery Depart-

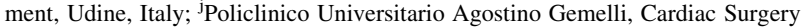
Department, Rome, Italy; ${ }^{k}$ Aarhus University Hospital Skejby, Cardiac Surgery
}

Department, Aarhus, Denmark; 'Edwards Lifesciences SA, Nyon, Switzerland and ${ }^{\mathrm{m}}$ Istituto Clinico San Ambrogio, Cardiac Surgery Department, Milan, Italy. This study was funded by Edwards Lifesciences, LLC.

Read at the 96th Annual Meeting of The American Association for Thoracic Surgery, Baltimore, Maryland, May 14-18, 2016.

Received for publication Aug 29, 2016; revisions received Aug 25, 2017; accepted for publication Sept 9, 2017.

Address for reprints: Christopher Young, MD, St Thomas' Hospital, London, United Kingdom (E-mail: chrisheartfix@live.co.uk).

$0022-5223 / \$ 36.00$

Copyright (c) 2017 by The American Association for Thoracic Surgery

https://doi.org/10.1016/j.jtcvs.2017.09.133 


$\begin{array}{ll}\text { Abbreviations and } & \text { Acronyms } \\ \text { ART } & =\text { anterior right thoracotomy } \\ \text { AVR } & \text { aortic valve replacement } \\ \text { EOA } & \text { effective orifice area } \\ \text { FOUNDATION = } & \text { Assessing Standard oF Care and } \\ & \text { Clinical Outcomes UsiNg the } \\ & \text { EDWARDS INTUITY VAlve } \\ & \text { SysTem in a European multI- } \\ & \text { center, Active, pOst-market } \\ & \text { surveillaNce Study } \\ = & \text { full sternotomy } \\ \text { FS } & =\text { minimally invasive surgery } \\ \text { MIS } & \text { New York Heart Association } \\ \text { NYHA } & =\text { patient-prosthesis mismatch } \\ \text { PPM } & =\text { paravalvular leak } \\ \text { PVL } & \text { repid-deployment aortic valve } \\ \text { RDAVR } & =\text { upper hemisternotomy } \\ \text { UHS } & =\text { crossclamp time } \\ \text { XCT } & \end{array}$

- Scanning this $\mathrm{QR}$ code will take you to a supplemental video for the article.

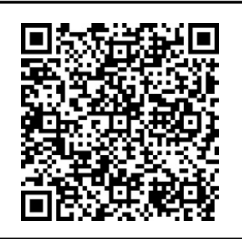

Surgical aortic valve replacement (AVR) is the principal therapy for patients with severe aortic stenosis. A recent study of 82 million Medicare beneficiaries aged 65 years or older reported that the adjusted rate of AVR increased $1.6 \%$ per year from 1999 to $2011,{ }^{1}$ culminating in a prevalence estimate of $2 \%$ to $7 \%$ in individuals aged more than 65 years $^{2}$ and in the elderly (aged $>75$ years) the pooled prevalence of all aortic stenosis was $12.4 \%$ and the prevalence of severe aortic stenosis was $3.4 \% .^{3}$ A UK audit database recently analyzed changes in treatment of aortic stenosis and regurgitation and reported a $26 \%$ increase in the number of patients undergoing aortic valve surgery and a $70 \%$ increase in implants in octogenarians. ${ }^{4}$ Worldwide AVR procedures are expected to increase to more than 800,000 annually by the year 2050 , although much of this growth will likely be transcatheter AVR. ${ }^{5}$ The proportion of patients receiving tissue valves as opposed to mechanical valves has been recently increasing, especially in younger patients in whom the prospect of lifelong anticoagulation therapy is unappealing and fraught with risks.

AVR with bovine pericardial valves has been commercially used for more than 20 years. ${ }^{6}$ Technologic advances in valve design and materials continue to improve the procedural success and long-term safety and performance of surgical aortic valves. One recent design improvement has been introduced providing for a shaped skirt along the underside of the valve; the skirt acts to mechanically maintain effective orifice area (EOA) in aortic placement and to provide a substrate for fixation and an associated significantly reduced need for suturing. Such new valves are termed "rapid-deployment valves" because their implantation (rapid-deployment aortic valve replacement [RDAVR]) requires only 3 sutures and facilitates being implanted with less-invasive surgical access than traditional AVR.

Recent clinical trial results have been reported for the rapid-deployment EDWARDS INTUITY valve (Edwards Lifesciences, LLC, Irvine, Calif). In the randomized CADENCE-MIS study, investigators showed the minimally invasive surgery (MIS) group enabled with this valve to be implanted faster, with significantly shorter aortic crossclamp time (XCT) and better hemodynamics compared with the full sternotomy (FS) group receiving conventional surgical AVR valves. ${ }^{7}$ Further, the TRITON study highlighted that isolated RDAVR with this valve facilitated MIS and led to low hospital mortality. ${ }^{8-10}$ Most recently, the TRANSFORM trial demonstrated reduced XCT and cardiopulmonary bypass times compared with the Society of Thoracic Surgeons database, low incidences of clinical safety complications, and impressive effectiveness outcomes. ${ }^{11}$ Still, data outside the setting of a clinical trial, coming to be even more in demand in the present era of evidence-based medicine and real-world outcomes, have not yet been reported with this valve. The present study reports short-term outcomes of the Assessing Standard oF Care and Clinical Outcomes UsiNg the EDWARDS INTUITY VAlve SysTem in a European multI-center, Active, pOst-market surveillaNce Study (FOUNDATION) registry, representing the largest series of patients receiving the EDWARDS INTUITY valve system in a registry setting.

\section{MATERIALS AND METHODS Study Design}

The FOUNDATION registry was a prospective, multicenter, singlearm, postmarket 2-year study designed to determine the safety and effectiveness of the EDWARDS INTUITY rapid-deployment valve system in a broad registry setting across Europe. The study protocol was in compliance with ISO 14155:2011, 2007/47/EC European Medical Device Directive, MedDev 2.12-1, 2.7.4, 2.12.2, as well as directives 90/385/EEC and 93/42/EEC. The ICH E6 GCP Good Clinical Practices was also used for guidance. The study is listed on clinicaltrials.gov NCT02338154. The study protocol was approved by each investigational center's local ethics committee.

\section{Study Cohort}

Patients were approached for participation if they were aged 18 years or more, had pure aortic stenosis or predominant aortic stenosis combined with aortic insufficiency, and were scheduled to undergo replacement of their native aortic valve or a previously implanted aortic valve prosthesis. 
Those patients excluded had a history of active endocarditis within 3 months of the scheduled operation or if diagnosed with pure aortic insufficiency or aneurysm of the aortic root or ascending aorta. Patient solicitation for participation in this registry was based on individual selection by the surgeon on the basis of an appropriate risk profile and surgical preference. Written informed consent was provided by all study subjects.

\section{Implant Procedure}

The valve system evaluated includes the EDWARDS INTUITY Valve System (Model 8300A), available in sizes between 19 and $27 \mathrm{~mm}$, and the EDWARDS INTUITY Delivery System (Model 8300D). The surgical intervention was decided on by each investigator according to each patient's situation. Implantation of the test valve was attempted whether as an isolated AVR or concomitantly with other necessary surgical procedure(s). Video 1 shows an exemplary implantation of this valve system via an upper hemisternotomy (UHS). After hockey-stick aortotomy crossing the sinotubular junction, the native aortic valve leaflets were removed and annular calcium was carefully debrided. Sizing of the study valve was carried out meticulously, confirming the next smaller and bigger valve size as inappropriate. Three equidistant guiding sutures were placed through the nadir of the aortic annulus and the valve sewing ring. The valve system was then seated and secured onto the annulus. The balloon catheter was then inflated to the appropriate pressure to deploy the stent frame in a controlled, rapid fashion. Once deployed, the prosthesis was situated in a supra-annular position with the stent skirt frame seated below the annulus in a flared configuration. With the skirt frame deployed, the delivery system and valve holder were removed, the guiding sutures were tied down, and the aortotomy was closed. Patients converted to another valve were not followed (per protocol) and are not reported upon. Postoperative anticoagulation management was left to physician discretion.

\section{Safety and Effectiveness End Points}

Safety end points included all-cause mortality, study valve-related mortality, hemolysis, endocarditis, thromboembolic events, study valve thrombosis, major paravalvular leaks (PVLs), bleeding events, study valve explant or reoperation, structural deterioration of study valve, and nonstructural deterioration of study valve, all according to the standardized classifications of the Society of Thoracic Surgeons/American Association for Thoracic Surgery. ${ }^{12}$ Major PVL was defined as any grade PVL requiring intervention. All adverse events and safety outcomes were reviewed and adjudicated by an independent Clinical Events Committee. For our analysis, we prospectively counted all events within 30 days of the index surgery as early events; events occurring after 30 days are reported as such, independently of admission status.

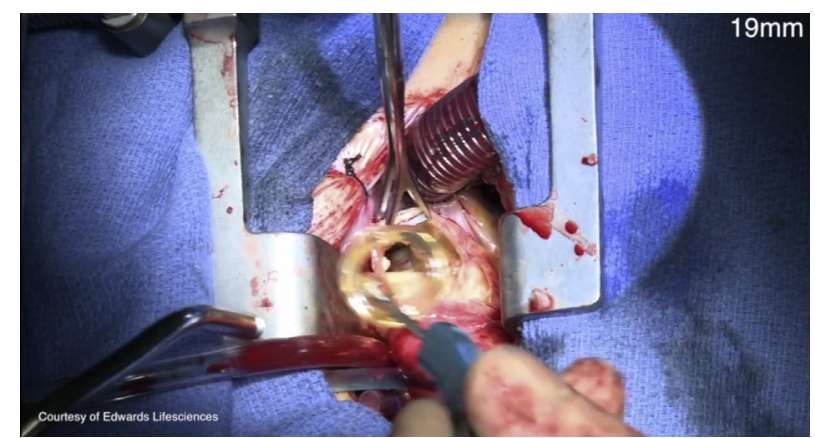

VIDEO 1. Technical aspects of minimally invasive AVR using the UHS approach. The video shows and describes the technical aspects of implantation of the study valve using the UHS approach. Video available at: http:// www.jtcvsonline.org/article/S0022-5223(17)32375-9/fulltext.
Effectiveness end points included device technical success, procedural technical success, valve implantation time, XCT, cardiopulmonary bypass time, and New York Heart Association (NYHA) functional class. Device technical success was defined as the successful deployment of the study valve and retrieval of the delivery system, with the subject leaving the operating room with the investigational prosthesis in place. Procedural technical success was defined as device technical success followed by the absence of adverse events resulting in device reoperation, implant of permanent pacemaker (with baseline sinus rhythm and no preexisting baseline conduction abnormalities), or valve-related death within 10 days of index procedure or discharge, whichever comes first.

Valve hemodynamic end points included mean and peak pressure gradient, EOA, and EOA index (defined as EOA divided by patient body surface area). Severe patient-prosthesis mismatch (PPM), defined as an EOA index less than $0.65 \mathrm{~cm}^{2} / \mathrm{m}^{2}$, was to be analyzed in patients at 1 year. All hemodynamic data were to be analyzed by an independent echocardiographic core laboratory; however, missing echocardiographic measures from the core laboratory were replaced with measures assessed from the individual investigational centers.

\section{Follow-up}

Patients were followed for up to 2 years after the index surgery, with clinic visits after 3 months and 1 year and telephone assessment at 30 days and 2 years. Safety outcomes were evaluated at 30 days, 3 months, and 1 and 2 years. Valve hemodynamic end points were evaluated at baseline, discharge, 3 months, and 1 year. In addition, the NYHA functional class assessments were collected at baseline and after 30 days, 3 months, and 1 and 2 years. All analyses were based on a data extract date of December 16, 2016

\section{Statistical Analysis}

Summary statistics for continuous variables included the number and percentage of subjects with a value for the variable of interest, as well as the mean and standard deviation, unless otherwise noted; non-normal continuous variables are also reported as median and [interquartile range]. Early safety events were calculated as the number of patients with the event divided by the number of patients. Safety events occurring at more than 30 days of the index procedure were calculated as linearized rates, the number of these events divided by the time of follow-up beyond 30 days. Kaplan-Meier analyses were used to analyze time to first occurrence of each primary safety event. The freedom from each event type at 1 year is reported, along with the standard error per Greenwood's formula. For the analysis of valve hemodynamic data, a longitudinal mixed effects model was used to account for repeated measures. For the analysis of patient NYHA functional class data, a 1-sided binomial test was used to determine whether significantly more than $50 \%$ of the patients had an improved NYHA class assessment at 1 year compared with baseline.

\section{RESULTS}

\section{Baseline Patient Characteristics}

Between July 2012 and July 2014, 517 patients were enrolled at 26 centers in 9 European countries. Baseline characteristics are detailed in Table 1. The patient cohort reflected that of a typical AVR population. Mean age was $75.5 \pm$ 6.4 years, and $43.1 \%$ were female. Society of Thoracic Surgeons risk score was $2.5 \pm 2.3$, and mean $\log$ European System for Cardiac Operative Risk Evaluation II was 7.1 \pm 4.9.

\section{Procedural Outcomes}

The study valve was successfully implanted in 493 $(95.4 \%)$ of the 517 enrolled patients. Twenty-four patients 
TABLE 1. Preoperative characteristics of the enrolled patient cohort

\begin{tabular}{|c|c|}
\hline Characteristic & Summary \\
\hline Age, y & $75.5 \pm 6.4(45,91)(\mathrm{n}=516)$ \\
\hline Female & $223 / 517(43.1 \%)$ \\
\hline BMI & $28.1 \pm 4.9(16.5,51.0)(\mathrm{n}=503)$ \\
\hline BSA & $1.9 \pm 0.2(1.3,2.6)(\mathrm{n}=503)$ \\
\hline Myocardial infarction & $22 / 516(4.3 \%)$ \\
\hline $\begin{array}{l}\text { Cardiac rhythm abnormalities/ } \\
\text { conduction disturbances* }\end{array}$ & $138 / 516(26.7 \%)$ \\
\hline Preexisting pacemaker or ICD & $26 / 516(5.0 \%)$ \\
\hline $\begin{array}{l}\text { Hyperlipidemia or } \\
\text { hypercholesterolemia }\end{array}$ & $270 / 516(52.3 \%)$ \\
\hline Rheumatic fever & $8 / 516(1.6 \%)$ \\
\hline History of smoking & $134 / 516(26.0 \%)$ \\
\hline Alcohol/drug abuse & $9 / 516(1.7 \%)$ \\
\hline Blood diatheses & $22 / 516(4.3 \%)$ \\
\hline Calcium metabolic disorders & $7 / 516(1.4 \%)$ \\
\hline Cancer & $79 / 516(15.3 \%)$ \\
\hline Obesity (BMI $\geq 30$ ) & $151 / 503(30.0 \%)$ \\
\hline Liver disease & $24 / 516(4.7 \%)$ \\
\hline Renal failure/insufficiency & $53 / 516(10.3 \%)$ \\
\hline euroSCORE II & $7.1 \pm 4.9(1.5,48.3)(\mathrm{n}=516)$ \\
\hline STS score & $2.5 \pm 2.3(0.4,27.2)(\mathrm{n}=448)$ \\
\hline NYHA class I & $40 / 433(9.2 \%)$ \\
\hline NYHA class II & $200 / 433(46.2 \%)$ \\
\hline NYHA class III & $178 / 433(41.1 \%)$ \\
\hline NYHA class IV & $15 / 433(3.5 \%)$ \\
\hline
\end{tabular}

$B M I$, Body mass index; $B S A$, body surface area; $I C D$, International Classification of Diseases; euroSCORE, European System for Cardiac Operative Risk Evaluation; STS, Society of Thoracic Surgeons; NYHA, New York Heart Association. *Includes sinus tachycardia, sinus bradycardia, bradycardia-tachycardia, atrial fibrillation/supraventricular tachycardia, atrial flutter, ventricular tachycardia, and other cardiac rhythm abnormalities.

were converted to another commercial valve. The main reasons for conversions were apparent valve or delivery system malfunction $(\mathrm{n}=8)$, improper positioning $(\mathrm{n}=4)$, PVL $(\mathrm{n}=2)$, difficult anatomy or calcification preventing delivery $(n=2)$, tear at the aortic sinus $(n=1)$, tear at the valvular annulus $(\mathrm{n}=1)$, improper sizing $(\mathrm{n}=1)$, or valve pop-out $(\mathrm{n}=1)$. Device technical success was $95.4 \%(493 /$ 517), and procedural success was $91.4 \%$ (469/513). All reported results hereafter reflect the 493 patients who successfully received the study valve implant.

Of the 493 patients, $336(68 \%)$ received isolated AVR and $157(32 \%)$ underwent additional concomitant surgery. Of the patients receiving isolated AVR, $166(49 \%)$ were operated via FS and $170(51 \%)$ underwent an MIS approach via a UHS $(\mathrm{n}=134,40 \%)$ or anterior right thoracotomy (ART) $(\mathrm{n}=36,11 \%)$. Implanted study valve sizes were $19 \mathrm{~mm}$ in $15.0 \%(73 / 486), 21 \mathrm{~mm}$ in $27.6 \%(134 / 486)$, $23 \mathrm{~mm}$ in $32.7 \%(159 / 486) 23,25 \mathrm{~mm}$ in $18.7 \%$
(91/486), and $27 \mathrm{~mm}$ in 6.0\% (29/486). Prosthesis size was $22.5 \pm 2.2 \mathrm{~mm}$ (median, $23 \mathrm{~mm}$ ).

XCTs for patients receiving isolated AVR undergoing FS, UHS, and ART were 47.3 \pm 14.9 minutes, $52.0 \pm 14.8$ minutes, and $73.3 \pm 17.9$ minutes, respectively. Cardiopulmonary bypass times in those undergoing isolated AVR were $67.2 \pm 19.3$ minutes for FS, $79.4 \pm 22.3$ minutes for UHS, and $104.2 \pm 19.7$ minutes for ART.

\section{Safety Outcomes}

Of the 493 patients, 467 (95\%) underwent follow-up at 30 days, $453(92 \%)$ underwent follow-up at 3 months, $388(79 \%)$ underwent follow-up at 1 year, and 376 $(76 \%)$ underwent follow-up at 2 years. The total patient follow-up time was 869.8 patient-years, representing a follow-up of $1.8 \pm 0.7$ years (median: $2.0[1.9,2.1]$ ); aggregate follow-up beyond 30 days was 830.4 patientyears $(1.7 \pm 0.7 ; 1.9[1.8,2.0])$. Safety outcomes are listed in Table 2 . There were 45 all-cause deaths, 15 early $(3.0 \%)$ and 30 (3.6\%/patient-year) at more than 30 days; of these, $7(1.4 \%)$ early and $12(1.4 \%$ /patient-year) at more than 30 days were related to the valve. There were early major bleeding events in 30 patients $(6.1 \%)$, $6(1.2 \%)$ related to anticoagulation; beyond 30 days, there was 1 major bleeding event $(0.1 \%$ /patient-year), which was related to anticoagulation. Major PVL was reported with 6 events early in 5 patients $(1.0 \%)$ and 9 events beyond 30 days in 8 patients $(1.1 \%$ /patientyear). Early and greater than 30 days thromboembolic events were reported in 19 patients $(3.9 \%)$ and 13 $(1.6 \%$ /patient-year) events in 12 patients, respectively. There were 7 early reoperation events in 6 patients $(1.2 \%)$ and 9 reoperation events beyond 30 days in 8 patients $(1.1 \% /$ patient-year). New pacemaker implantation occurred in $6.1 \%$ of the patients early and $1.0 \% / \mathrm{pa}-$ tient-year beyond 30 days.

\section{Hemodynamics}

Valve hemodynamics are listed in Table 3 and shown as box plots in Figure 1. Across all study valve sizes, EOA increased from $0.72 \pm 0.3 \mathrm{~cm}^{2}$ at baseline to $1.85 \pm 0.7 \mathrm{~cm}^{2}$ at discharge and $1.88 \pm 0.6 \mathrm{~cm}^{2}$ at 1 year. Mean gradient decreased from $47.6 \pm 16.9 \mathrm{~mm} \mathrm{Hg}$ at baseline to $11.6 \pm 7.0 \mathrm{~mm} \mathrm{Hg}$ at discharge and $9.6 \pm 4.6 \mathrm{~mm} \mathrm{Hg}$ at 1 year. Peak gradient decreased from $77.6 \pm 26.6 \mathrm{~mm} \mathrm{Hg}$ at baseline to $17.7 \pm 7.3 \mathrm{~mm} \mathrm{Hg}$ at 1 year. EOA index increased from $0.39 \pm 0.2 \mathrm{~cm}^{2} / \mathrm{m}^{2}$ at baseline to $1.01 \pm 0.3 \mathrm{~cm}^{2} / \mathrm{m}^{2}$ at 1 year; at 1 year, 28 of 287 patients $(9.76 \%)$ had severe PPM. EOA, EOA index, mean gradient, and peak gradient all exhibited significant changes from baseline to discharge ( $P<.0001$ for each). These measures at discharge were clinically sustained throughout 1 year of follow-up. 
TABLE 2. Safety end points of patients receiving the study valve

\begin{tabular}{|c|c|c|c|}
\hline \multicolumn{4}{|c|}{ All events (device related and nondevice related) } \\
\hline \multirow[b]{2}{*}{ Outcome } & \multirow{2}{*}{$\frac{\text { Early events }}{\mathrm{m}, \mathrm{n}(\mathrm{n} / \mathbf{N})}$} & \multicolumn{2}{|c|}{ Events at $>\mathbf{3 0} \mathrm{d}$} \\
\hline & & $\overline{\mathbf{m}, \mathbf{n}(\mathbf{m} / \mathbf{y}>\mathbf{3 0} \mathrm{d})}$ & Freedom from event at $1 \mathrm{y}(\mathrm{SE})$ \\
\hline All-cause mortality & $15,15(3.0 \%)$ & $30,30(3.6 \%)$ & $0.935(0.011)$ \\
\hline Study valve-related mortality & $7,7(1.4 \%)$ & $12,12(1.4 \%)$ & $0.966(0.008)$ \\
\hline Thromboembolic events & $19,19(3.9 \%)$ & $13,12(1.6 \%)$ & $0.945(0.010)$ \\
\hline Study valve thrombosis & $1,1(0.2 \%)$ & $0,0(0.0 \%)$ & $0.998(0.002)$ \\
\hline Bleeding event & $34,31(6.3 \%)$ & $5,4(0.6 \%)$ & $0.932(0.011)$ \\
\hline Major bleeding event & $33,30(6.1 \%)$ & $1,1(0.1 \%)$ & $0.939(0.011)$ \\
\hline Bleeding related to anticoagulation & $7,6(1.2 \%)$ & $1,1(0.1 \%)$ & $0.988(0.005)$ \\
\hline Major PV leak & $6,5(1.0 \%)$ & $9,8(1.1 \%)$ & $0.976(0.007)$ \\
\hline Endocarditis & $0,0(0.0 \%)$ & $5,5(0.6 \%)$ & $0.993(0.004)$ \\
\hline Structural valve deterioration & $0,0(0.0 \%)$ & $0,0(0.0 \%)$ & $1.000(0.000)$ \\
\hline Nonstructural valve deterioration & $0,0(0.0 \%)$ & $0,0(0.0 \%)$ & $1.000(0.000)$ \\
\hline Hemolysis & $2,2(0.4 \%)$ & $3,3(0.4 \%)$ & $0.989(0.005)$ \\
\hline Reoperation & $7,6(1.2 \%)$ & $9,8(1.1 \%)$ & $0.975(0.007)$ \\
\hline Explant & $4,4(0.8 \%)$ & $6,6(0.7 \%)$ & $0.983(0.006)$ \\
\hline Pacemaker implantation & $30,30(6.1 \%)$ & $8,8(1.0 \%)$ & $0.923(0.012)$ \\
\hline
\end{tabular}

$\mathrm{m}$ is the number of events. $\mathrm{n}$ is the number of subjects with an event. $\mathrm{N}=493$ valve-related deaths are any events in which valve relatedness is yes, indeterminate, or missing. Major PV leaks are any events of PV leak that required surgical intervention or were considered a serious adverse event. Nonstructural valve deterioration events exclude PV leak events. Based on Kaplan-Meier analysis of time to first occurrence. Standard error based on Greenwood's formula. SE, Standard error; $P V$, paravalvular.

\section{Functional Outcomes}

The NYHA functional class status of patients is detailed in Table 4. Overall, after 1 year of implant, 293 of 364 patients $(80.5 \%)$ improved in NYHA class, 63 of 364 patients $(17.3 \%)$ exhibited no change, and 8 of 364 patients $(2.2 \%)$ worsened. The proportion of patients who improved after 1 year was significantly greater than $50 \%(P<.0001)$. Of patients with a baseline NYHA class of II, III, and IV, and with measures at 1 year, 133 of $167(79.6 \%), 148$ of $150(98.7 \%)$, and 12 of $12(100 \%)$, respectively, improved after 1 year.

\section{DISCUSSION}

This FOUNDATION registry represents a broad European commercial experience with the EDWARDS INTUITY valve system. The safety profile of the valve system proved good. Over a follow-up period of 870 patientyears, the valve system was safe and performed well, albeit over a mean follow-up of only 1.8 years. These results confirm the valve system's clinical study data to be safe and effective. We observed 3.0\% early all cause mortality and 3.6\%/patient-year mortality beyond 30 days, both comparable to the rates previously reported for this valve. With this valve system, the TRITON trial reported $1.7 \%$ early mortality and $3.7 \%$ /patient-year at more than 30 days, ${ }^{8}$ whereas the CADENCE-MIS trial reported $4 \%$ early mortality and 6\%/patient-year beyond 30 days. $^{7}$ The TRANSFORM trial reported $0.8 \%$ early mortality, with freedom from mortality at 1 year of $0.964 .{ }^{11} \mathrm{We}$ observed valve-related mortality to be $1.4 \%$ early and
$1.4 \%$ /patient-year beyond 30 days, within the range of those reported with this valve in TRITON, ${ }^{9}$ CADENCEMIS, ${ }^{7}$ and TRANSFORM. ${ }^{11}$ Patients also exhibited noteworthy improvement in NYHA functional class with the study valve.

The incidence of major bleeding that we observed is comparable to previous reports with this and other valves. We observed major bleeding in $6.1 \%$ of patients early and in $0.1 \% /$ patient-year beyond 30 days. Unfortunately, the registry setting precludes a deep assessment into the major bleeding events, as well as strictly mandating the followup schedule. This $6.1 \%$ early incidence is slightly greater than seen in the CADENCE-MIS trial with this valve $(4 \%)^{7}$ and the Perceval S valve (Sorin Biomedica Cardio Srl, Saluggia, Italy, $4.3 \%){ }^{13}$ The $0.1 \%$ patient-year rate beyond 30 days is lower than reported in these 2 studies, $6 \%$ and $1.9 \%$, respectively.

Paravalvular regurgitation is key to the success of RDAVR. Early reports of the Perceval device reported worryingly high rates at $15.8 \% .{ }^{14}$ More recent studies report low PVL rates for the Perceval (2.6\% at 12 months) and EDWARDS INTUITY prostheses. We found a major PVL incidence of $1.0 \%$ early and $1.1 \%$ /patient-year beyond 30 days, similar to that reported in TRITON $(1.4 \%)^{9}$ and CADENCE-MIS $(0 \%)$.

\section{Implantation Success}

Our results show the study valve to be relatively easy to implant, with device technical and procedural successes 
TABLE 3. Hemodynamics of patients receiving the study valve

\begin{tabular}{|c|c|c|c|c|c|c|c|c|c|}
\hline Parameter & Visit & $19 \mathrm{~mm}$ & $21 \mathrm{~mm}$ & $23 \mathrm{~mm}$ & $25 \mathrm{~mm}$ & $27 \mathrm{~mm}$ & Overall & $\begin{array}{c}\text { Baseline } \\
\text { vs } \\
\text { discharge* }^{*}\end{array}$ & $\begin{array}{c}\text { Discharge } \\
\text { through } \\
1 \mathbf{y} \dagger \\
\end{array}$ \\
\hline \multirow[t]{4}{*}{ EOA } & Baseline & $59: 0.62 \pm 0.2$ & $108: 0.71 \pm 0.3$ & $132: 0.75 \pm 0.3$ & $78: 0.74 \pm 0.3$ & $20: 0.81 \pm 0.3$ & $402: 0.72 \pm 0.3$ & $<.0001$ & .0189 \\
\hline & Discharge & $58: 1.17 \pm 0.4$ & $99: 1.66 \pm 0.5$ & $122: 2.00 \pm 0.6$ & $68: 2.18 \pm 0.7$ & $20: 2.83 \pm 0.9$ & $368: 1.85 \pm 0.7$ & & \\
\hline & $3 \mathrm{mo}$ & $56: 1.14 \pm 0.4$ & $99: 1.59 \pm 0.5$ & $119: 1.86 \pm 0.6$ & $77: 2.10 \pm 0.6$ & $24: 2.54 \pm 0.8$ & $377: 1.77 \pm 0.7$ & & \\
\hline & $1 \mathrm{y}$ & $45: 1.28 \pm 0.3$ & $83: 1.61 \pm 0.4$ & $98: 1.97 \pm 0.4$ & $60: 2.23 \pm 0.7$ & $26: 2.64 \pm 0.7$ & $313: 1.88 \pm 0.6$ & & \\
\hline \multirow{4}{*}{$\begin{array}{l}\text { EOA } \\
\text { index }\end{array}$} & Baseline & $59: 0.37 \pm 0.1$ & $108: 0.41 \pm 0.2$ & $129: 0.40 \pm 0.2$ & $78: 0.37 \pm 0.1$ & $20: 0.40 \pm 0.1$ & $399: 0.39 \pm 0.2$ & $<.0001$ & .1565 \\
\hline & Discharge & $49: 0.69 \pm 0.3$ & $79: 0.92 \pm 0.3$ & $94: 1.05 \pm 0.3$ & $54: 1.15 \pm 0.3$ & $18: 1.40 \pm 0.5$ & $295: 0.99 \pm 0.4$ & & \\
\hline & $3 \mathrm{mo}$ & $48: 0.69 \pm 0.2$ & $87: 0.91 \pm 0.3$ & $89: 0.99 \pm 0.4$ & $58: 1.09 \pm 0.3$ & $20: 1.23 \pm 0.4$ & $303: 0.95 \pm 0.4$ & & \\
\hline & $1 \mathrm{y}$ & $41: 0.76 \pm 0.2$ & $79: 0.92 \pm 0.3$ & $94: 1.06 \pm 0.2$ & $52: 1.13 \pm 0.3$ & $21: 1.30 \pm 0.5$ & $287: 1.01 \pm 0.3$ & & \\
\hline \multirow[t]{4}{*}{ LVEF } & Baseline & $66: 66.71 \pm 9.9$ & $112: 65.87 \pm 11.9$ & $134: 64.56 \pm 11.7$ & $83: 60.57 \pm 12.82$ & $23: 62.96 \pm 9.3$ & $424: 64.24 \pm 11.8$ & .4618 & .3425 \\
\hline & Discharge & $66: 66.05 \pm 11.4$ & $113: 64.16 \pm 11.6$ & $132: 65.87 \pm 10.7$ & $74: 60.45 \pm 12.62$ & $25: 61.12 \pm 13.4$ & $413: 64.08 \pm 11.8$ & & \\
\hline & $3 \mathrm{mo}$ & $57: 64.58 \pm 7.0$ & $105: 66.26 \pm 9.9$ & $128: 65.20 \pm 9.5$ & $81: 62.36 \pm 11.32$ & $26: 63.08 \pm 10.2$ & $400: 64.65 \pm 9.8$ & & \\
\hline & $1 \mathrm{y}$ & $40: 64.28 \pm 8.1$ & $76: 64.64 \pm 8.2$ & $93: 64.65 \pm 9.0$ & $62: 63.30 \pm 7.8$ & $22: 63.64 \pm 9.3$ & $295: 64.23 \pm 8.5$ & & \\
\hline \multirow{4}{*}{$\begin{array}{l}\text { Mean } \\
\text { gradient }\end{array}$} & Baseline & $67: 51.22 \pm 21.2$ & $117: 49.11 \pm 16.8$ & $141: 47.51 \pm 16.7$ & $85: 44.36 \pm 13.32$ & $25: 44.83 \pm 14.8$ & $442: 47.64 \pm 16.9$ & $<.0001$ & $<.0001$ \\
\hline & Discharge & $69: 15.83 \pm 8.4$ & $126: 11.74 \pm 6.4$ & $139: 10.69 \pm 6.0$ & $84: 10.69 \pm 7.7$ & $27: 7.77 \pm 3.0$ & $449: 11.63 \pm 7.0$ & & \\
\hline & $3 \mathrm{mo}$ & $62: 14.58 \pm 8.3$ & $107: 10.96 \pm 6.0$ & $133: 9.73 \pm 6.0$ & $82: 8.34 \pm 4.7$ & $26: 7.38 \pm 2.8$ & $413: 10.41 \pm 6.4$ & & \\
\hline & $1 \mathrm{y}$ & $50: 13.16 \pm 6.9$ & $91: 10.14 \pm 4.3$ & $110: 8.96 \pm 3.7$ & $67: 8.45 \pm 3.0$ & $28: 7.25 \pm 3.1$ & $348: 9.63 \pm 4.6$ & & \\
\hline \multirow{4}{*}{$\begin{array}{l}\text { Peak } \\
\text { gradient }\end{array}$} & Baseline & $67: 83.75 \pm 33.2$ & $119: 78.92 \pm 28.2$ & $144: 77.08 \pm 25.1$ & $86: 73.11 \pm 20.92$ & $25: 72.51 \pm 21.2$ & $447: 77.36 \pm 26.6$ & $<.0001$ & $<.0001$ \\
\hline & Discharge & $69: 29.42 \pm 12.8$ & $126: 21.88 \pm 10.5$ & $141: 20.29 \pm 9.8$ & $85: 19.78 \pm 12.32$ & $28: 14.00 \pm 5.6$ & $453: 21.68 \pm 11.4$ & & \\
\hline & $3 \mathrm{mo}$ & $62: 27.46 \pm 13.6$ & $109: 21.12 \pm 10.3$ & $134: 19.48 \pm 11.9$ & $82: 16.52 \pm 7.8$ & $26: 14.00 \pm 5.0$ & $416: 20.24 \pm 11.4$ & & \\
\hline & $1 \mathrm{y}$ & $50: 23.88 \pm 8.6$ & $93: 18.29 \pm 7.2$ & $109: 16.97 \pm 6.8$ & $69: 15.40 \pm 4.9$ & $28: 13.29 \pm 5.4$ & $351: 17.68 \pm 7.3$ & & \\
\hline
\end{tabular}

All data are presented as $\mathrm{n}$ : mean \pm standard deviation. $E O A$, Effective orifice area; $L V E F$, left ventricular ejection fraction. *Mixed models with valve size and visit as parameters were used to model echocardiography over time. $P$ values for change from baseline to discharge are based on estimates from the mixed model. $\dagger P$ values for sustained improvement at (discharge, 3 months, and 1 year) with no significant changes in mean value postprocedure based on mixed models with valve size and echocardiography date as parameters.

of $95 \%$ and $91 \%$, respectively, even with investigators many of whom had little to no prior experience with this device. Other investigators report similar implantation rates with RDAVR. Shrestha and colleagues ${ }^{15}$ reported a 95.6\% implantation rate for the Perceval. There is always some learning curve associated with any new valve design. The newer second-generation INTUITY Elite valve was designed to be easier to implant, with greater technical success. Still, robust experience and keen judgment are needed to implant RDAVR systems in noncircular annuli, such as bicuspid valve pathology, or in annuli with high commissures and deep sinuses.

\section{Device Hemodynamics}

The EDWARDS INTUITY valve was designed with a stent feature, deploying in the left ventricular outflow tract, intended to maximize hemodynamic flow. The noteworthy hemodynamics we observed in this large registry confirm smaller reports. We observed a mean EOA at 1 year of $1.88 \pm 0.6 \mathrm{~cm}^{2}$, which compares favorably to the EAO of
$1.5 \pm 0.3 \mathrm{~cm}^{2}$ of the Perceval $\mathrm{S}^{13,16}$ and with $1.67 \pm 0.4 \mathrm{~cm}^{2}$ from the ATS $3 \mathrm{f}$ Enable (ATS Medical Inc, Minneapolis, Minn) valve. ${ }^{17}$ The mean and peak valve gradients we observed further solidify other reports of this valve's hemodynamics: $9.6 \pm 4.6 \mathrm{~mm} \mathrm{Hg}$ and $17.7 \pm 7.3 \mathrm{~mm} \mathrm{Hg}$ at 1 year were comparable to $9.1 \pm 2.9 \mathrm{~mm} \mathrm{Hg}$ and $16.9 \pm 5.3 \mathrm{~mm} \mathrm{Hg}$ reported by Borger and colleagues, ${ }^{7}$ and the TRITON trial's $8.4 \pm 3.4 \mathrm{~mm} \mathrm{Hg}$ and $15.8 \pm 5.7 \mathrm{~mm} \mathrm{Hg}$.

It appears the hemodynamic performance of the study device exceeds that of standard Magna devices (Edwards Lifesciences) implanted with a sutured technique. ${ }^{18}$ The reason for this may be that the frequent use of Teflon felt pledgets in the left ventricular outflow tract is avoided with the study valve; second, its flared frame may increase the left ventricular outflow tract's effective diameter by making it more circular, thereby positively affecting the continuity equation and improving laminar flow.

With these hemodynamics, it is unexpected that PPM should feature is this series; and indeed $9.76 \%$ severe 


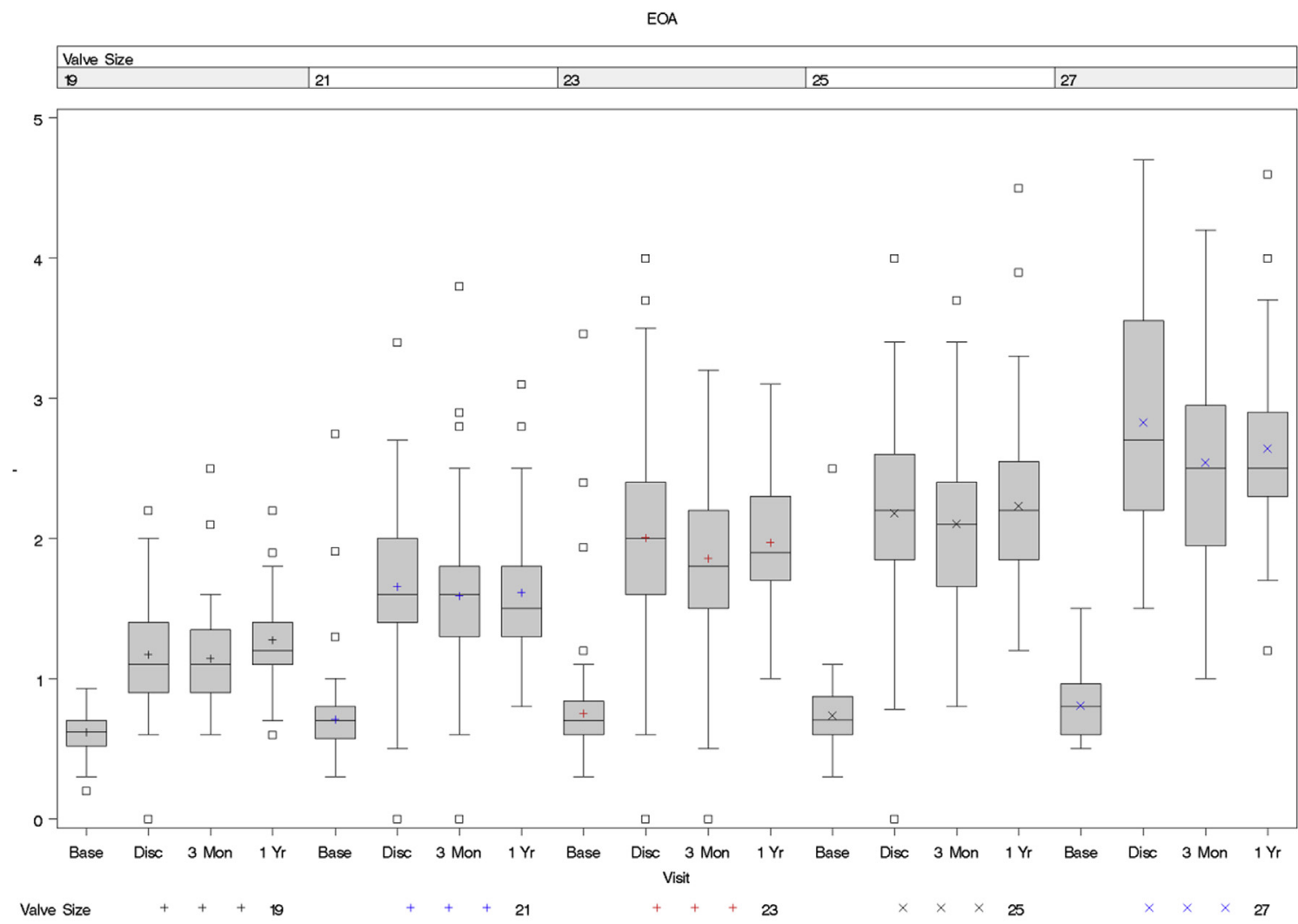

- EUUA Inaex

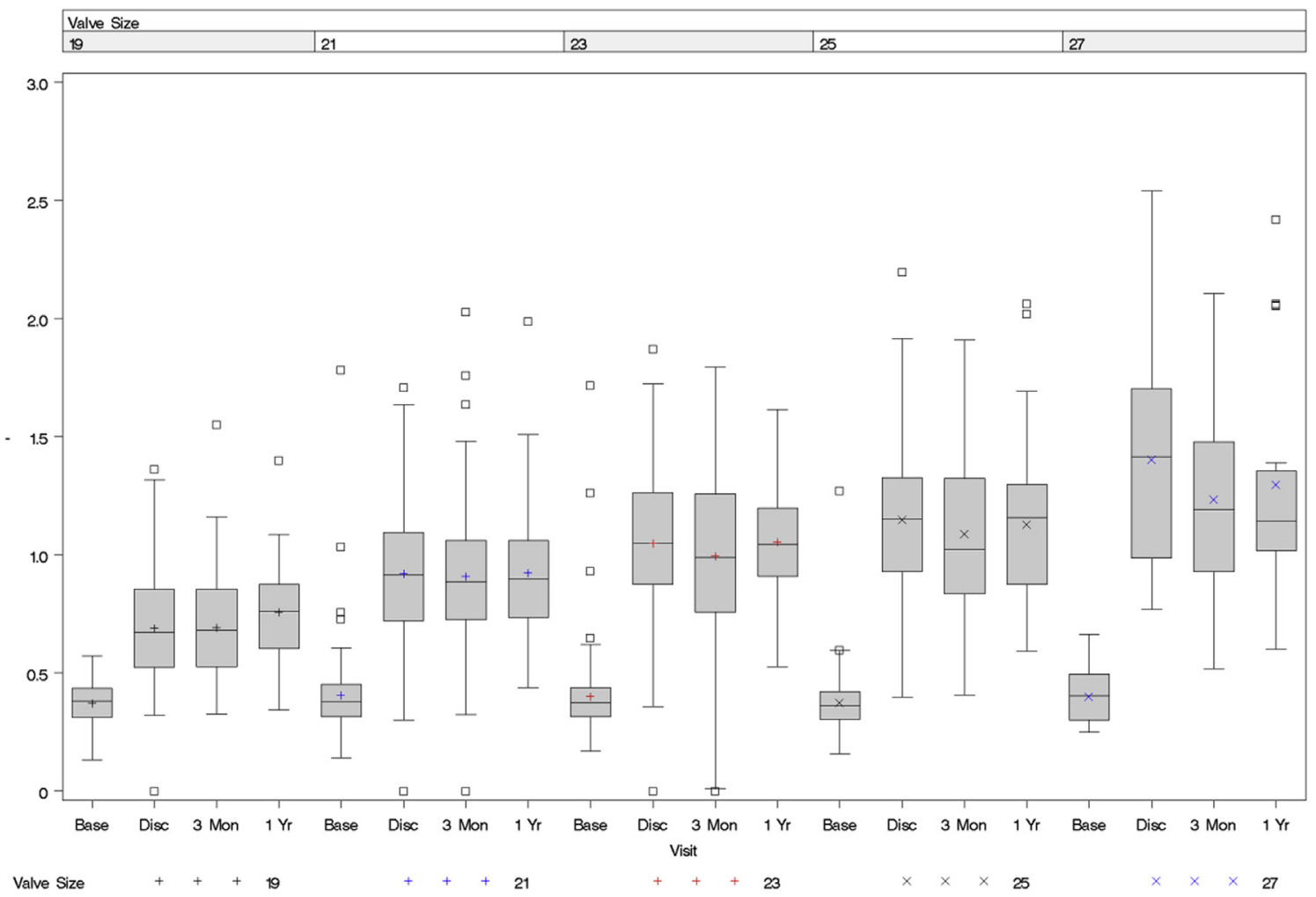

FIGURE 1. Various hemodynamic measures, illustrated as box plots, at baseline (base), discharge (Disc), 3 months, and 1 year. 

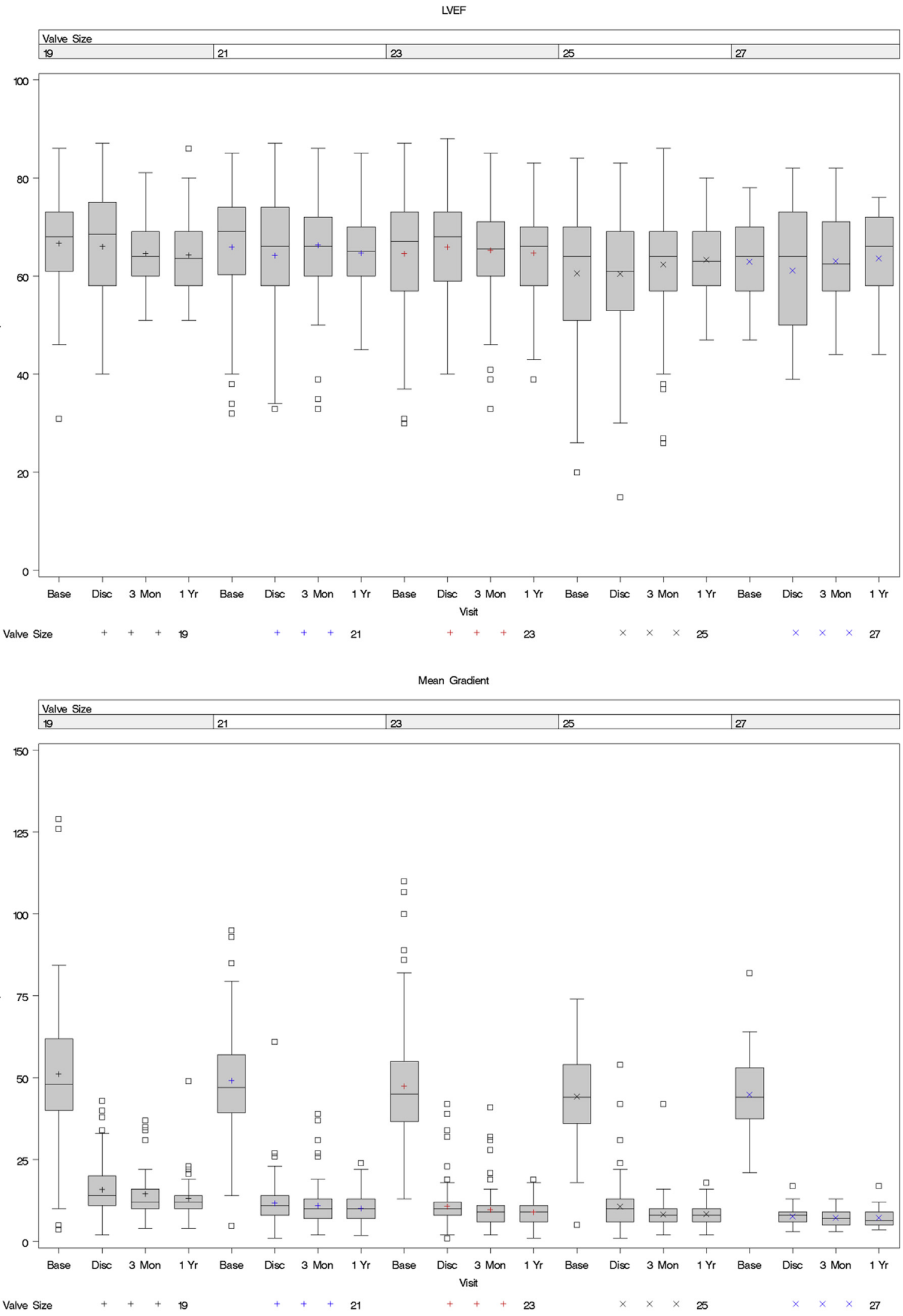

FIGURE 1. (Continued). 


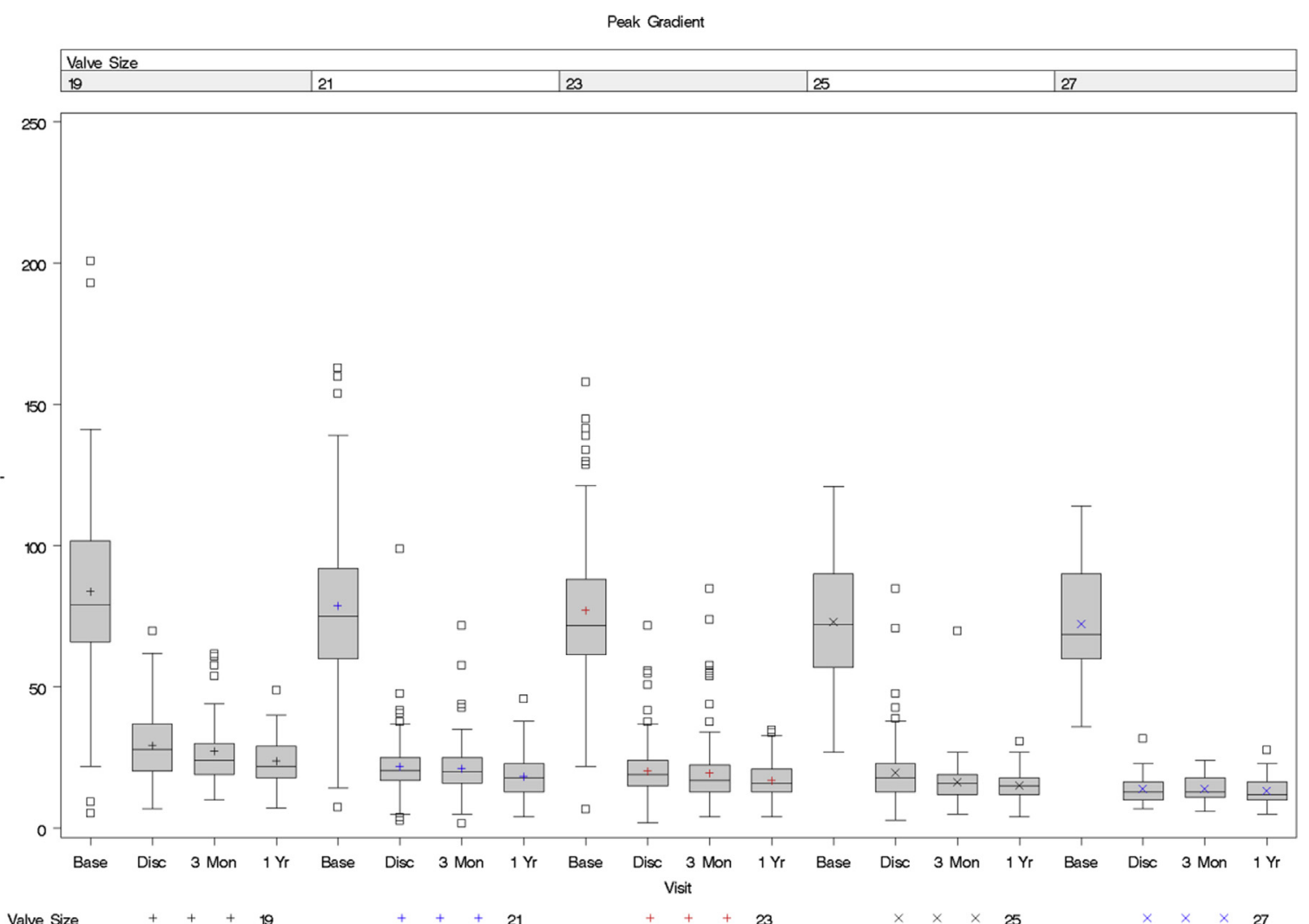

FIGURE 1. (Continued).

PPM at 1 year is exemplary, especially given this registry's $43 \%$ proportion of small $19-$ and $21-\mathrm{mm}$ valves. Device sizing is critical; in this series, standard sizing criteria were used, but there was also a deliberate tendency not to oversize. We think that the high incidence of small valves in this registry reflects the cohort rather than undersizing. In routine clinical practice, PPM is a concern, especially in patients with small valve sizes. The incidence of severe PPM is being increasingly reported; however, its consequence is still unclear. ${ }^{19}$

\section{Pacemaker Implantation}

Pacemaker implantation is a complication of AVR. In this registry, we experienced a pacemaker rate of $6.1 \%$, slightly higher than the CADENCE-MIS experience with this valve of $4 \%,{ }^{7}$ although lower than the TRANSFORM trial's $11.9 \% .{ }^{11}$ Other rapid-deployment valves have exhibited higher rates of pacemaker implantation: Perceval S: 7\% to $17 \%,{ }^{13,16,20}$ ATS 3f Enable: $7 \%$ to $7.3 \%{ }^{17,21}$

\section{Minimally Invasive Surgery Implantation}

That $51 \%$ of isolated AVR cases were performed under MIS with this study valve significantly exceeded that expected. In Europe, MIS AVR rates are relatively low, with Germany reporting $25 \%{ }^{22}$ and the United Kingdom reporting only $8 \%$. The high rate in this registry might have partly been due to the cohort, but the study valve clearly lends itself to an MIS approach. Any heart valve prosthesis that increases MIS

TABLE 4. New York Heart Association functional class status of patients receiving the study valve

\begin{tabular}{|c|c|c|c|c|c|}
\hline \multirow[b]{3}{*}{ NYHA at $1 y$} & \multicolumn{4}{|c|}{ Preoperative NYHA } & \multirow[b]{3}{*}{$P$ value } \\
\hline & Class I & Class II & Class III & Class IV & \\
\hline & $\mathbf{N}=\mathbf{4 1}$ & $\mathbf{N}=\mathbf{2 2 2}$ & $\mathbf{N}=197$ & $\mathbf{N}=\mathbf{2 1}$ & \\
\hline Class I & $7.0 \%(28 / 401)$ & $33.2 \%(133 / 401)$ & $25.7 \%(103 / 401)$ & $2.2 \%(9 / 401)$ & $<.0001$ \\
\hline Class II & $1.7 \%(7 / 401)$ & $8.2 \%(33 / 401)$ & $11.2 \%(45 / 401)$ & $0.5 \%(2 / 401)$ & \\
\hline Class III & $0.0 \%(0 / 401)$ & $0.2 \%(1 / 401)$ & $0.5 \%(2 / 401)$ & $0.2 \%(1 / 401)$ & \\
\hline Class IV & $0.0 \%(0 / 401)$ & $0.0 \%(0 / 401)$ & $0.0 \%(0 / 401)$ & $0.0 \%(0 / 401)$ & \\
\hline Death/explant/reoperation & $0.5 \%(2 / 401)$ & $4.5 \%(18 / 401)$ & $3.2 \%(13 / 401)$ & $1.0 \%(4 / 401)$ & \\
\hline
\end{tabular}

Percentages are based on the number of subjects who have a postoperative NYHA assessment or who died, underwent explantation, or underwent a study valve reoperation before the upper limit of the 1-year visit window. $P$ value is based on testing if the binomial proportion of subjects with improved NYHA at 1 year is $50 \%$. NYHA, New York Heart Association. 
is welcomed, and this prosthesis has shown that the increased $\mathrm{XCT}$ generally associated with MIS is negated by this valve, as a $24 \%$ reduction in XCT that CADENCE-MIS demonstrated when comparing conventional surgical AVR sutured through FS to the study valve inserted via UHS. ${ }^{23}$

In all types of cardiac surgery, resternotomy is associated with increased mortality. However, resternotomy after UHS or ART approaches are straightforward because the right ventricle is not adherent to the posterior table of the sternum. In the past few years, the percentage of bioprosthetic implants has increased significantly, particularly in younger age groups. Therefore, it can be expected that there will be an increase in revision valve procedures in the future. If the study device facilitates an increase in MIS, then it can be expected that the mortality of repeat surgical interventions may be significantly reduced by use of de novo RDAVR under MIS.

MIS AVR has been shown to improve operative mortality, with a risk ratio of 0.74 for mini-AVR versus FS. ${ }^{24}$ The mean surgical age for AVR has increased over the last 10 years and patient comorbidities have increased. Adoption of MIS techniques has shown improved outcomes, ${ }^{25,26}$ and RDAVR technology can contribute to improved outcomes by maximizing MIS uptake.

\section{Study Limitations}

The FOUNDATION Registry was a single-arm study with nonconsecutive enrollment and without an active comparator group. Therefore, it is vulnerable to selection and channeling biases. No roll-in cases were permitted among naïve operators, so the outcomes reflect the impact of a learning curve. Over the course of the registry, considerable emphasis was placed on procedural training and the sharing of best practices. Nonetheless, the possibility of performance bias cannot be excluded.

\section{CONCLUSIONS}

The FOUNDATION registry is a broad, multicenter European registry evaluating the safety and performance of the EDWARDS INTUITY valve system. The results confirm the valve system's impressive safety profile through 2 years and hemodynamic performance through 1 year. The high rate of valve insertion via an MIS approach suggests that this valve enhances and facilitates MIS approaches.

\section{Conflict of Interest Statement}

C.Y.: consultant and proctor to Edwards Lifesciences. G.L.: consultant to Edwards Lifesciences. A.K.: consulting fees from Edwards Lifesciences. B.K.P.: clinical consultant for Edwards Lifesciences and Sorin. J.I.A.: proctor for Edwards Lifesciences. J.A.: travel and accommodation to national and international meetings from Edwards Lifesciences. C.G.: Edwards Lifesciences employee; equity ownership in Edwards Lifesciences. M.G.: Speaker's Bureau: Edwards
Lifesciences, LivaNova; Proctor: LivaNova. All other authors have nothing to disclose with regard to commercial support.

The authors thank Bettina Groll, $\mathrm{PhD}$, at Edwards Lifesciences for assistance in the development of this article, and the statistical team at Edwards Lifesciences.

\section{References}

1. Barreto-Filho JA, Wang Y, Dodson JA, Desai MM, Sugeng L, Geirsson A, et al Trends in aortic valve replacement for elderly patients in the United States, 19992011. JAMA. 2013;310:2078-85.

2. Nkomo VT, Gardin JM, Skelton TN, Gottdiener JS, Scott CG, EnriquezSarano M. Burden of valvular heart diseases: a population-based study. Lancet 2006;368:1005-11.

3. Osnabrugge RL, Mylotte D, Head SJ, Van Mieghem NM, Nkomo VT, LeReun CM, et al. Aortic stenosis in the elderly: disease prevalence and number of candidates for transcatheter aortic valve replacement: a meta-analysis and modeling study. J Am Coll Cardiol. 2013;62:1002-12.

4. Dunning J, Gao H, Chambers J, Moat N, Murphy G, Pagano D, et al. Aortic valve surgery: marked increases in volume and significant decreases in mechanical valve use-an analysis of 41,227 patients over 5 years from the Society for Cardiothoracic Surgery in Great Britain and Ireland National database. J Thorac Cardiovasc Surg. 2011;142:776-82.e773.

5. Hoerstrup SP, Weber B. Biological heart valves. Eur Heart J. 2015;36:325-6.

6. Bourguignon T, Bouquiaux-Stablo AL, Candolfi P, Mirza A, Loardi C, May MA, et al. Very long-term outcomes of the Carpentier-Edwards Perimount valve in aortic position. Ann Thorac Surg. 2015;99:831-7.

7. Borger MA, Dohmen PM, Knosalla C, Hammerschmidt R, Merk DR, Richter M, et al. Haemodynamic benefits of rapid deployment aortic valve replacement via a minimally invasive approach: 1-year results of a prospective multicentre randomized controlled trial. Eur J Cardiothorac Surg. 2016;50:713-20.

8. Haverich A, Wahlers TC, Borger MA, Shrestha M, Kocher AA, Walther T, et al. Three-year hemodynamic performance, left ventricular mass regression, and prosthetic-patient mismatch after rapid deployment aortic valve replacement in 287 patients. J Thorac Cardiovasc Surg. 2014;148:2854-60.

9. Kocher AA, Laufer G, Haverich A, Shrestha M, Walther T, Misfeld M, et al. Oneyear outcomes of the Surgical Treatment of Aortic Stenosis With a Next Generation Surgical Aortic Valve (TRITON) trial: a prospective multicenter study of rapid-deployment aortic valve replacement with the EDWARDS INTUITY Valve System. J Thorac Cardiovasc Surg. 2013;145:110-6.

10. Wahlers TC, Haverich A, Borger MA, Shrestha M, Kocher AA, Walther T, et al. Early outcomes after isolated aortic valve replacement with rapid deployment aortic valve. J Thorac Cardiovasc Surg. 2016;151:1639-47.

11. Barnhart GR, Accola KD, Grossi EA, Woo YJ, Mumtaz MA, Sabik JF, et al TRANSFORM (Multicenter Experience With Rapid Deployment Edwards IN TUITY Valve System for Aortic Valve Replacement) US clinical trial: perfor mance of a rapid deployment aortic valve. J Thorac Cardiovasc Surg. 2017 153:241-51.e242.

12. Akins CW, Miller DC, Turina MI, Kouchoukos NT, Blackstone EH, Grunkemeier GL, et al. Guidelines for reporting mortality and morbidity after cardiac valve interventions. J Thorac Cardiovasc Surg. 2008;135:732-8.

13. Folliguet TA, Laborde F, Zannis K, Ghorayeb G, Haverich A, Shrestha M. Sutureless Perceval aortic valve replacement: results of two European centers. Ann Thorac Surg. 2012;93:1483-8.

14. D’Onofrio A, Messina A, Lorusso R, Alfieri OR, Fusari M, Rubino P, et al. Sutureless aortic valve replacement as an alternative treatment for patients belonging to the "gray zone" between transcatheter aortic valve implantation and conventional surgery: a propensity-matched, multicenter analysis. J Thorac Cardiovasc Surg. 2012;144:1010-6.

15. Shrestha M, Fischlein T, Meuris B, Flameng W, Carrel T, Madonna F, et al. European multicentre experience with the sutureless Perceval valve: clinical and haemodynamic outcomes up to 5 years in over 700 patients. Eur J Cardiothorac Surg. 2016;49:234-41.

16. Fischlein T, Meuris B, Hakim-Meibodi K, Misfeld M, Carrel T, Zembala M, et al. The sutureless aortic valve at 1 year: a large multicenter cohort study. J Thorac Cardiovasc Surg. 2016;151:1617-26.e1614.

17. Martens S, Sadowski J, Eckstein FS, Bartus K, Kapelak B, Sievers HH, et al. Clinical experience with the ATS $3 \mathrm{f}$ Enable(R) Sutureless Bioprosthesis. Eur J Cardiothorac Surg. 2011;40:749-55. 
18. Bobiarski J, Newcomb AE, Elhenawy AM, Maganti M, Bos J, Hemeon S, et al. One-year hemodynamic comparison of Perimount Magna with St Jude Epic aortic bioprostheses. Arch Med Sci. 2013;9:445-51.

19. Morita S. Aortic valve replacement and prosthesis-patient mismatch in the era of transcatheter aortic valve implantation. Gen Thorac Cardiovasc Surg. 2016;64:435-40.

20. Mazine A, Teoh K, Bouhout I, Bhatnagar G, Pelletier M, Voisine P, et al. Sutureless aortic valve replacement: a Canadian multicentre study. Can J Cardiol. 2015;31:63-8.

21. Vola M, Ruggieri VG, Campisi S, Grinberg D, Morel J, Favre JP, et al. Sutureless 3f Enable valve implantation concomitant with mitral valve surgery. Interact Cardiovasc Thorac Surg. 2015;21:169-75.

22. Hamm CW, Mollmann H, Holzhey D, Beckmann A, Veit C, Figulla HR, et al. The German Aortic Valve Registry (GARY): in-hospital outcome. Eur Heart J. 2014;35:1588-98.

23. Borger MA, Moustafine V, Conradi L, Knosalla C, Richter M, Merk DR, et al. A randomized multicenter trial of minimally invasive rapid deployment versus conventional full sternotomy aortic valve replacement. Ann Thorac Surg. 2015;99:17-25.
24. Phan K, Tsai YC, Niranjan N, Bouchard D, Carrel TP, Dapunt OE, et al. Sutureless aortic valve replacement: a systematic review and meta-analysis. Ann Cardiothorac Surg. 2015;4:100-11.

25. Merk DR, Lehmann S, Holzhey DM, Dohmen P, Candolfi P, Misfeld M, et al Minimal invasive aortic valve replacement surgery is associated with improved survival: a propensity-matched comparison. Eur J Cardiothorac Surg. 2015; 47:11-7.

26. Kaneko T, Loberman D, Gosev I, Rassam F, McGurk S, Leacche M, et al. Reoperative aortic valve replacement in the octogenarians-minimally invasive technique in the era of transcatheter valve replacement. J Thorac Cardiovasc Surg. 2014;147:155-62.

Key Words: aortic valve replacement, bioprosthesis, heart valve, hemodynamics 